\title{
Research
}

\section{Community paramedicine through multiple stakeholder lenses using a modified soft systems methodology}

Angela Martin BN, GDipN(Emerg), Dip.ParaSci(Amb), DipMgt, Cert IV Training \& Assessment is a PhD candidate'; Peter O'Meara BHA, MPP, PhD is Adjunct Professor ${ }^{2}$

\author{
Affiliations: \\ ${ }^{1}$ La Trobe University, Mildura, Victoria \\ ${ }^{2}$ Department of Paramedicine, School of Primary and Allied Health Care, Faculty of Medicine, Nursing \& Health Science, Monash \\ University, Melbourne, Victoria
}

https://doi.org/10.33151/ajp.17.793

\begin{abstract}
Introduction

Community paramedicine (CP) is an emerging model of care which expands paramedic scopes of practice to collaboratively support primary healthcare delivery in underserviced and disadvantaged communities. $\mathrm{CP}$ is a patient-centred holistic approach focussed on improving health outcomes, with success heavily reliant on integrative partnerships. This research aimed to identify key stakeholder perspectives about the value of CP in rural Australia.
\end{abstract}

\section{Methods}

A workshop was conducted using a modified soft system methodology (SSM) that asked participants to consider the value of CP from the perspective of five key stakeholder groups. The 50 participants consisted of paramedics and volunteer ambulance officers, paramedic service executives, paramedic educators, Medicare Local representatives and a general practitioner. Participants were randomly allocated to five stakeholder groups: paramedic profession; Minister for Health and Ageing; consumers, chief executive and executive management team of an ambulance service; and healthcare professionals. The application of SSM placed the five groups into three broad categories of stakeholders: customers, actors, and owners.

'Customers' in this context are patients, families and carers. 'Actors' are paramedics and volunteer ambulance officers, and ambulance service executives. The 'owners' are the Office of the Minister and those with the power to facilitate or block initiatives. Participants were allocated 15 minutes to brainstorm the question: "What can a community paramedic do for you to improve rural health provision?" Group views were verbally shared with all workshop participants and video recorded for analysis.

\section{Results}

The 'customers' asked about CP from patient, family and carer perspectives, and were highly engaged with questions about how, when and where CP could operate. The paramedic and volunteer ambulance officer group of 'actors' battled to move beyond their emergency response mindset to articulate a clear CP vision. The executive management team responded from a strategic and risk management perspective focussing on patient safety and corporate image. They identified the need to form stakeholder partnerships. The 'owners' representing the Office of the Minister focussed on the holistic and wellness benefits of CP. The health professional group anticipated the CP role could provide collaborative care and support doctors.

\section{Conclusions}

The findings suggest many participants had a limited understanding of CP, which creates a barrier for implementation. Key benefits identified included a reduction in financial and physical burdens on the rural healthcare sector and improved outcomes for consumers. Active participation of stakeholders in the process of introducing CP programs, where people are comfortable 
questioning current practices and encouraged to explore new concepts and innovations, would enable a shared understanding of program aims and expectations. For paramedic services to expand service delivery models in rural Australia community participation and engagement with stakeholders is essential. They and paramedics must be willing to embrace meaningful and collaborative partnerships with patients, broader health networks, social services, politicians and researchers, and be prepared to step away from their traditional 'command and control' culture to co-design innovative paramedic models. SSM was a worthwhile approach to stakeholder engagement that has the potential to improve implementation of community paramedic programs through improved inclusion and the valuing of stakeholder perspectives.

Keywords:

community paramedic; consumer engagement; healthcare; patient-centred; primary care; rural health

Corresponding Author: Angela Martin, angela.martin@sa.gov.au 


\section{Introduction}

Mounting fiscal pressure, ageing populations, increased service demand and limited resources drives governments and other funders to explore innovative ways of delivering healthcare. Over the past two decades, utilising paramedics for the management of non-urgent, low-acuity illnesses and injuries, primary healthcare interventions and health education has expanded and is generally described as 'community paramedicine' (1). Community paramedicine $(\mathrm{CP})$ is an emerging model of care where paramedics utilise an expanded skill set to collaboratively support the chronic disease and primary healthcare management for consumers in underserviced rural communities (2). In North America, the CP role has evolved to extend beyond the conventional emergency scope of practice to include the application of specialised skills and training based on community needs (3).

Around the globe, the CP concept is visible in other contemporary paramedic models such as extended care paramedics (ECPs) in Australia, New Zealand and the United Kingdom, and mobile integrated healthcare $(\mathrm{MIH})$ in the United States. Like community paramedics, ECPs treat lower acuity cases in the home or residential care facilities, with hospital avoidance being the primary focus (4). ECPs often play a vital role in dispatch centre triaging of calls to manage or reduce paramedic service demand by redirecting calls to alternative care pathways (5). The main difference between the community paramedic and ECP roles is the point of intervention in the patient journey, with community paramedics strongly aligned with a collaborative and proactive public health approach, while ECPs remain essentially reactive, responding to and treating patients who have requested an ambulance (6). $\mathrm{MIH}$ in the US, which characteristically embeds medical dominance and professional control over paramedics, is predominately designed to reduce hospital attendance and improve health outcomes by targeting individuals deemed high volume ambulance utilisers (7). MIH community paramedics provide patient transport to alternative care locations other than emergency departments, provide follow-up discharge care and partner with community health workers and primary care providers in underserved areas to provide preventive care (8). Although there is growing evidence supporting the benefits of $\mathrm{CP}$, particularly in North American studies (2,3,9-18), evidence supporting the effectiveness of MIH remains largely anecdotal (19).

Although advocates of CP appreciate the significant benefits and outcomes for consumers and the broader healthcare system, resistance from stakeholders is evident due to a lack of rigorous data reported on program performance $(20,21)$. Limited knowledge and understanding of the concept or just natural resistance to the introduction of an alternative model of care are barriers to consider. The successful implementation of a new healthcare model is dependent on factors related to the intervention itself, the process of implementation and the context in which the intervention is situated (22). Therefore, engaging stakeholder viewpoints and participation at the grassroots stage of program implementation is imperative to ensure that differing perspectives and insights have been listened to and taken into consideration (21). This research aimed to explore the opinions, understandings and perspectives of $\mathrm{CP}$ through the lenses of various key stakeholder groups, by asking participants to explore 'What can a community paramedic do for you to improve rural health provision?'

\section{Methods}

\section{Setting}

The research team enlisted the support of a paramedicine professional organisation, Paramedics Australasia (South Australian Chapter), to facilitate a participatory workshop in Adelaide, the capital city of South Australia. Participants were asked to consider the research question from the perspective of different stakeholder groups. The research team facilitated a workshop titled 'Community Paramedic: What is it?'

\section{Participants}

Participants were predominately drawn from the South Australian Ambulance Service (SAAS), with others drawn from other health providers interested in improving access to health services in South Australia. The 50 participants consisted of SAAS paramedics, volunteer ambulance officers, executive and operations managers, paramedic educators, Medicare Local representatives and a general practitioner.

\section{Study design}

An overarching objective was to make the workshop a learning activity, as well as being interactive and engaging. The workshop was designed around the concepts associated with soft systems methodology (SSM) to challenge attendees to engage in conversation and consider the benefits of $\mathrm{CP}$ from a stakeholder perspective other than their own. This is consistent with recommendations that when addressing system problems (in particular soft system problems involving human activities) all stakeholders should become participants through engagement in open debate and discussion (23). Through this approach, stakeholder groups should be able to overcome conflict and design a system acceptable to all - SSM uses models of purposeful activity systems to set up a debate about change and aims to find ways to implement changes that are both (systematically) desirable and feasible (24). The SSM process begins with at least one stakeholder proposing that something could be done better or differently to improve a situation and seeking the input and perspectives of others who may not have considered the problem situation before (22). Interactive methods such as workshops and focus groups are encouraged within SSM to gain a common understanding about the problem situation and the objectives of change $(22,25)$. 


\section{Procedures}

In the workshop, participants were randomly allocated to one of five groups and asked to answer a set of pre-prepared questions from the perspective of the five stakeholder groups that had been selected through the modified application of SSM. Their responses were not sought to necessarily reflect the actual views of the stakeholders; the intent was to evoke participation from the 'shoes of others' and enable a better understanding of the perspectives of others. Participants were not advised that they needed to specifically relate their findings back to rural South Australia. The research team identified key model-building components through the SSM mnemonic CATWOE, which categorises stakeholders as 'customers', 'actors' and 'owners' (26). The other components of the mnemonic - world view, transformation, environment - were not directly relevant to this exercise (27). Table 1 describes each of the key stakeholder groups that were identified for the purposes of the exercise.

Table 1. Stakeholder groups - customers, actors and owners

\begin{tabular}{|l|l|}
\hline \multicolumn{1}{|c|}{ Category } & \multicolumn{1}{|c|}{ Specific stakeholder group } \\
\hline Customers & Patients, carers and families \\
\hline Actors & $\begin{array}{l}\text { Paramedic profession (including volunteer } \\
\text { ambulance officers), chief executive (including } \\
\text { management team) of paramedic services }\end{array}$ \\
\hline Owners & $\begin{array}{l}\text { Minister for Health and Ageing (including } \\
\text { advisors), other healthcare professionals }\end{array}$ \\
\hline
\end{tabular}

The format of the workshop and data analysis followed a sevenstep process.

\section{Welcome and group allocation}

Fifty attendees including SAAS paramedics, volunteer ambulance officers, executive and operations managers, educators, Medicare Local representatives and a general practitioner were randomly allocated a pre-determined number ranging between 1 and 5 on their name tag, which they collected as they entered the workshop room. Attendees were divided into five groups of 10 and Paramedics Australasia committee members selected one attendee per group who they identified as a paramedic degree student, intern or junior paramedic to undertake a group facilitator 'wizard' role. As successfully trialled in a previous Australian paramedicine research study, junior attendees were selected for these facilitator 'wizard' roles to empower them to have a voice within their group, to delegate scribe and speaker positions and to keep discussion on track in the allocated timeframe (28). Focus groups often pose a challenge when it comes to power structures, with participants with lower levels of power or hierarchy feeling disregarded or participating to a lesser extent than those with higher levels of power, who may come across more outspoken and opinionated (22). In this instance, close attention was paid to the structures within each group to ensure that participation was fair and equitable.

\section{Overview of CP and the project by the research team - Q\&A opportunity}

The researchers presented findings from North American CP programs they had studied and introduced the concept of the Australian RESPIGHT model of care, which distinguishes CP from other emerging paramedic service innovations such as ECPs and MIH (3.9). Following the presentation and research outline, participants were given the opportunity to question the presenters in an open forum on their research findings, current projects and vision for the implementation of CP programs and associated education in Australia.

\section{Group memberships revealed}

Each of the groups were asked to answer the research question from the perspective of their designated stakeholder group and summarise their collective views with the 'wizards', with researchers assisting as required. The five stakeholder groups appointed and explored in this study were: paramedic professionals; Minister for Health and Ageing and team of advisors; consumers; chief executive and executive management team of paramedic services; and healthcare professionals (doctors, nurses, allied health professionals).

\section{Data collection}

Each 'wizard' was provided with a laminated card with their allocated stakeholder group and the question 'What can a community paramedic do for you to improve rural health provision?' scribed on one side. On the opposite side of the card, 'wizards' and their groups were provided with 'conversation starter' tips to consider and support discussion (Table 2). Each group was given 15 minutes to brainstorm their answers and scribe them on butcher's paper from their stakeholder group's perspective. At the conclusion of 15 minutes, a spokesperson from each group presented their responses to all participants. These responses, questions and discussion were video recorded for later transcription and analysis.

\section{Transcription and analysis}

Thematic analysis techniques using manual methods consistent with the recommendations of Strauss and Corbin were adopted for transcribing, de-identifying and coding these data. These techniques allowed identification of common themes, without the constraint of establishing how themes linked together (29). Independent analysis of transcripts by a second researcher supported the reliability of coding and validity of the themes identified. Researchers encouraged all participants to share and exchange their thoughts and knowledge with others in their appointed stakeholder group with an appointed scribe and group facilitator 'wizard' (30). This ensured participants were comfortable and provided with an appropriate space for brainstorming discussion and pre-determined questions on flip cards, and tools for the recording of data (30). The researchers closely monitored the discussions and engagement within the groups and noted their observations directly after the workshop had concluded. Participants shared their group findings 
immediately following their brainstorming discussions, to evoke further conversation and provide an element of rapid feedback to the groups consistent with SSM (22).

\section{Ethics approval}

Ethics approval was granted by La Trobe University Human Research Ethics Committee (FHEC 12/8). Attendees were provided with participant information statements and consent forms and advised that participation was voluntary. They had the option to withdraw their participation in the workshop at any time until 4 weeks after the workshop. Participants were forewarned that consent would include agreeing to the video recording of each group's summaries and discussion points for later transcription and analysis.

\section{Results}

The application of SSM placed the five groups into three broad categories of stakeholders: 'customers, 'actors' and 'owners', even though in the real-world individual groups can and do overlap. The 'customers' asked questions about CP from patient, family and carer perspectives and were highly engaged, with those senior managers in attendance keen to listen and engage with this perspective. The consumer group had questions about how, when and where community

Table 2. Tips for stakeholder group exercise

\begin{tabular}{|c|c|c|}
\hline Stakeholder group & Tips for group & Consider \\
\hline Paramedic profession & $\begin{array}{l}\text { You represent the paramedic profession } \\
\text { as a whole, ie. paramedics, ambulance } \\
\text { officers, volunteer ambulance officers, } \\
\text { emergency operations centre staff, } \\
\text { paramedic students }\end{array}$ & $\begin{array}{l}\text { - The needs of rural paramedics/volunteers } \\
\text { - The needs of rural patients and how they differ to } \\
\text { metropolitan patients } \\
\text { - The availability of health services in rural communities } \\
\text { - Long term sustainable solutions to improve care } \\
\text { provision and service delivery to your rural patients }\end{array}$ \\
\hline $\begin{array}{l}\text { Minister for Health and } \\
\text { Ageing and team of } \\
\text { advisors }\end{array}$ & $\begin{array}{l}\text { You are the power brokers } \\
\text { You control allocation of funding and } \\
\text { resources to health services }\end{array}$ & $\begin{array}{l}\text { - Consumer needs (your voters) } \\
\text { - The healthcare profession as a whole } \\
\text { - Sustainable options to improving healthcare in rural } \\
\text { communities } \\
\text { - The immediate and long-term benefits of CP in rural } \\
\text { communities } \\
\text { - Demographics and ageing populations }\end{array}$ \\
\hline Consumers & $\begin{array}{l}\text { You, your family and friends are the } \\
\text { consumers of health care } \\
\text { You have little control over government } \\
\text { spending, but consumers are the voters, } \\
\text { therefore you have a right to have your } \\
\text { needs heard }\end{array}$ & $\begin{array}{l}\text { - Your needs and the needs of others (eg. elderly, } \\
\text { disabled, special needs, Indigenous, farmers, } \\
\text { homeless, substance dependant, mental health, } \\
\text { children) } \\
\text { - Your viewpoint of having a community paramedic } \\
\text { working collaboratively with other healthcare providers } \\
\text { in your community } \\
\text { - The differences between rural and metro health service } \\
\text { provision } \\
\text { - The availability of health services in rural communities }\end{array}$ \\
\hline $\begin{array}{l}\text { Chief executive and } \\
\text { executive management } \\
\text { team of a paramedic } \\
\text { service }\end{array}$ & $\begin{array}{l}\text { You are the power brokers of a } \\
\text { paramedic service } \\
\text { You control allocation of funding and } \\
\text { resources within the company }\end{array}$ & $\begin{array}{l}\text { - Consumer needs (your patients) } \\
\text { - Your employees' needs } \\
\text { - Long-term sustainable solutions to improve care } \\
\text { provision and service delivery to rural patients } \\
\text { - The immediate and long-term benefits of CP in rural } \\
\text { communities } \\
\text { - Demographics and ageing populations }\end{array}$ \\
\hline $\begin{array}{l}\text { Healthcare } \\
\text { professionals }\end{array}$ & $\begin{array}{l}\text { You are the healthcare professionals } \\
\text { who provide services to rural patients (ie. } \\
\text { doctors, nurses, allied health, carers) }\end{array}$ & $\begin{array}{l}\text { - The needs of rural patients and how they differ to } \\
\text { metropolitan patients } \\
\text { - The availability of health services in rural communities } \\
\text { - How a collaborative partnership with community } \\
\text { paramedics could improve patient outcomes and } \\
\text { service provision } \\
\text { - The immediate and downstream benefits to the health } \\
\text { department }\end{array}$ \\
\hline
\end{tabular}


could assist them; although they did not explicitly examine how programs might improve their quality of life or potentially reduce their ambulance and hospital utilisation, the group positively embraced exploring the concept of $\mathrm{CP}$.

'When will you be available to help? What services can you offer me as a carer or a patient in terms of education? The accessibility of referral pathways, how do we actually follow up on what you say we should be doing or who we should be seeing?'

Talking about special needs groups like Indigenous and mental health patients, how will you help when they are confused about their medications? What happens if I run out of medications?'

'My carer didn't come today; can I call you?'

'Can you help me if I'm unaware of available health services in the area, other than just calling an ambulance or going to an A\&E?'

'Will you provide me with a follow-up care plan after my hospital discharge?'

The paramedic and volunteer ambulance officer group of the 'actors' discussed their views of CP. They initially battled to articulate a clear vision of the benefits of CP.

'How would the relationships be altered with other health services, as we're not a registered health profession at this point in time [this is no longer the case] and we're still dealing with other registered health professions, so are we going to have contact with the aged services and physios? What kind of attitude is going to occur around that and how would you transition amongst the other allied health professions?'

'On a negative, there's some paramedics that might not like the interference with the down time because they're happier with a quieter shift load.'

'Would there be improved funding to actually put these extra staff into place?'

After moving beyond their emergency response mindset and identifying implementation barriers, the 'actors' group did support the potential career and skills advancement opportunities and overall value of the CP role.

'It would be really good to be able to gain extra skills and be also actively using skills that especially rural paramedics might not use all the time. Paramedics that are really interested in it can take it as a pathway.' 'It could possibly provide more career opportunities ... improved job satisfaction, so you're more connected to the community and actually getting to know the people that you're dealing with, so you've got a bit of a history with when them as well, you've got a better chance of getting a broader medical picture, rather than just going to treat them for that emergency call.'

'It could work as a preventative and or a maintenance issue for people, for example falls prevention.
Paramedics could do reviews on TNTs [treat not transport], so people that have been left at home for a particular reason, we can go back and check on them. That seems like a good way to access people.'

The executive management team approached the question from a strategic and risk management perspective focussing predominantly on patient safety, funding and corporate image.

'What can it do for us, as this would be good from a corporate image perspective? There would be lots of really good stories out of this. In line with that we thought there would be a very strong patient safety focus from the management team and in particular, looking at what we can do to mitigate potential risks.'

'There was certainly going to be cost savings through the health system because we're going to see fewer presentations at the hospital, for the hospital stays. That funding is very circular, and it should then feed back into the ambulance service, so it can then provide these levels of services to the communities. But there would need to be a change in the funding model.'

They identified advantages in better utilisation of resources and viewed $\mathrm{CP}$ as an alternative model of care not presently provided.

'We would view it as a sustainability measure for the ambulance service. It would provide better alternative models of care that we don't currently provide.'

'Decrease patient treatment times; transport of patients; better utilisation of resources and skills. So that fits into this whole model once we build the partnerships, we know who we're dealing with, we know what we're doing, we know what the relationships are with other providers we can then make sure we're utilising our resources to the maximum.'

This group identified the need to form stakeholder partnerships to understand the needs of communities before implementing a CP model.

'Stakeholder partnerships, certainly these would be at sort of global, corporate level, but also strategic management level, [and] at local levels. There are multiple tiers if you like about how we would engage with stakeholders ... we would be very much a part in rural areas about getting those relationships and Indigenous health engagement and that's probably a key part of that in many parts of South Australia.'

'Better healthcare coordination and a better understanding of community health needs, all feed into all of this. Once we've got a better handle on what's actually happening in those communities, all of this starts to come into play, so there would need to be a strong strategic oversight for the whole thing.' 
The 'owners' representing the Office of the Minister of Health and Ageing saw some participants switch into 'power mode', with a small number of senior participants dominating the discussion. The group raised some useful points for discussion focussing on the holistic and wellness benefits of the CP model and less on emergency paramedicine. The group discussed the value of utilising a community paramedic in consumers' homes and in rural emergency departments; while reflecting on a program SAAS had previously piloted which supported intensive care paramedics working with registered nurses in emergency departments in the absence of available GPs in the Murray Mallee and Bordertown regions in South Australia (31).

'We've focussed more on the holistic and wellness and less on emergency medicine, where we believe there were lots of dollars we saved there. We thought it was value added to the ED [emergency department], not only can they work in the home itself, but we run the same sort of systems as what we did back about 4 years ago.'

Other benefits noted included significant healthcare cost savings, improved consumer access, increased community education and a clinical stopgap between volunteer ambulance officer scopes of practice and GPs in rural settings. The latter through the introduction of a community paramedic who could see and treat consumers in the home avoiding unnecessary hospital attendances.

'Currently there's a gap between the volunteer and the doctor about taking the patient to hospital. Whereas the local community paramedic will perhaps not send every patient to hospital, so that they're stopping at home rather than sending them off to hospital.'

'Increased community education and we'll have access to the people a lot more frequently than what the doctors will.'

The group identified a reduced dependency in utilisation of services such as the Royal Flying Doctor Service and expedited discharges for patients with the community paramedic involved in home visits. The subsequent 'owners' group, the healthcare professionals, addressed the question by responding from the perspectives of their individual practice domains. This group's discussion demonstrated that the workshop participants had limited knowledge and understanding of the professional roles and boundaries of other healthcare professionals, as well as being unaware of services already available in the home. A common theme which emerged was how CP could open referral pathways and reduce workload for other health professionals.

'We started having a discussion about where we could proportion the spending or where we could make the most savings. We thought that putting more patients into the right care and the right pathways was obviously going to reduce the demand on more specific hospital- based services.'

'Hospital avoidance and decreasing the workload across specific areas of the system, making things more efficient from that perspective.'

The group considered CP from a doctor's perspective as a 'medical secretary type role', who could potentially decrease their day-to-day and on-call workload by doing the groundwork and paperwork with the patient, freeing the doctor up. However, they did not elaborate which services the community paramedic would offer in this regard.

'We felt as a group it could sort of fill in a medical secretary type role, where they [the community paramedic] do all of the groundwork and paperwork so that the doctor can then make those sorts of decisions based on the patient and probably from his (sic) perspective, decrease his (sic) day-to-day workload.' 'The social pathway side of thing; we looked at it from the point of view that a lot of the day to day appointments that GPs probably receive are based on more of a social need with a lot of the elderly demographic, so opening more referral pathways, gives them more options on a day-to-day basis for their patient; which may not necessarily mean them needing to come back to clinics.'

From a nursing perspective, the group suggested that integration and cross pollination between $\mathrm{CP}$ and nursing would improve referral pathway options for consumers, reduce workload pressure on nurses and redirect funding into the nursing training and education.

'From a nurse's perspective, we thought that it was improving referral care pathway. Things like the RDNS [Royal District Nursing Service] specific type role; there could be more integration within that and even some cross pollination of work related to those things.' 'A better way to allocate funding amongst the nursing work group for improved education opportunities.' 'The times of visits; it could make their needs shorter; more specific shorter role within each patient subset and a community paramedic could pick up some of the slack.'

From an allied health perspective, the group suggested CP could encourage consumer compliance with rehabilitation and physiotherapy exercises to reduce long term dependency on these services. The community paramedic could work in collaboration with allied health professionals to support holistic wellness to improve health outcomes, improve efficiencies and reduce hospital attendance.

'Encouraging compliance; checking up on the patients on a day-to-day basis; making sure they're doing their rehab, their exercises and those sorts of things. The 
long-term view is they're decreasing the reliance on those services. That's the benefit of collaboration.

Everyone is working together and addressing the whole picture.'

\section{Discussion}

With funding pressures, and rising political and consumer demands, the need to learn and adapt from innovative models of paramedic service delivery from across the globe has never been greater (32). Widespread problems with policy implementation, funding cuts, poorly integrated services across institutional settings, and few examples of successful multi-disciplinary teams have resulted in professional and consumer dissatisfaction with health service delivery (27). In this environment, it is a challenge to identify and implement paramedicine-related solutions that address these intrinsic health system problems in ways that build capacity among participants and produce sustainable outcomes.

Although not used extensively in the health sector, SSM represents one set of ideas that has demonstrated how progress can be made to overcome difficult situations embedded in complex social systems (27). It was applied to this research question because of its flexibility and adaptability in different contexts (22). A strength of SSM is its collaborative and participatory approach to problem solving and change management; intentionally seeking differing perspectives of customers to ensure that those responsible for delivering the service (actors and owners) have an understanding of what is important to the beneficiaries, based on acquired knowledge, not assumption (22). Fundamentally, SSM is designed to be a reflective process and in this case did cause a degree of discomfort for participants when asked to reflect on their views of the potential benefits of $C P$.

The workshop stakeholder groups identified key benefits of the $\mathrm{CP}$ role; specifically, the provision of alternative care pathways and collaborative partnerships to reduce financial and physical burden on the rural healthcare sector. As evidenced in the literature, it was argued that a patient-centred approach coupled with consumer engagement and consultation is pivotal to the success and sustainability of expanded practice roles and extended care $(10,33)$. However, the findings suggest that despite introducing the $\mathrm{CP}$ model of care at the beginning of the workshop, many participants still had a limited understanding of CP. In particular, its aim of supporting and expanding consumer access to essential primary healthcare services in under resourced and disadvantaged rural communities. Despite a high number of attendees at the workshop representing paramedics and paramedic service senior management, participants struggled to clearly identify how CP could improve rural health provision for consumers, suggesting limited understanding of $\mathrm{CP}$ and the roles of other health professionals. The conclusion is that challenging paramedics to consider themselves as pivotal players in public health, patient safety and health education, requires a change in mindset and an appreciation of the patient cycle of care (34).

These findings could suggest a metro centric bias among the predominately metropolitan-based participants; a lack of appreciation of rural health service deficits or a limited understanding of CP might have influenced the participants' ability to fully consider the benefits of CP or think outside of the traditional emergency response model of care. Additionally, the paramedic participants might have struggled to think beyond their traditional professional identity, which is typically immersed in medical emergencies and trauma responses (35). With paramedics now registered as health professionals through the Australian National Registration and Accreditation Scheme there are more opportunities for paramedics to be involved in shaping the identity of their profession and revolutionising the contribution paramedics can make in a patient's journey (34).

As paramedicine in Australia advances, knowledge and skill sets will expand beyond traditional scopes of practice, placing paramedics in a unique position to significantly impact on health outcomes. By understanding existing local health systems and identifying service gaps, paramedics can explore opportunities to better integrate with other healthcare providers. In order to continue to evolve as a profession, paramedics need to be comfortable examining healthcare matters through the lenses of other stakeholders and the changing environmental context (36). Participants in this workshop identified that CP programs can bring stakeholders such as paramedics, nurses, allied health professionals, social services and GPs together to deliver patient-centred care $(3,9,12,14)$.

Utilising the SSM process to develop and implement CP programs was a promising approach with the potential to allow all stakeholder perspectives to be heard and valued; in particular the customer perspective, which is imperative to achieving locally responsive, patient-centred outcomes (22). SSM has previously been used to critically appraise the pre-hospital practitioner model as an alternative to traditional paramedicine models of care (37). Despite positive findings in 2003, the pre-hospital practitioner model has not fully evolved in Australia and illustrates a limitation of SSM; it is more frequently adopted to make recommendations for improvement in healthcare than to take action to implement and evaluate outcomes from findings (22). A methodological limitation of the use of SSM in this research was that the make-up of the participant group was predominately drawn from one organisation and one professional group. The limited time available to fully discuss and debate the issues identified was another constraint. In addition, the underpinning use of SSM carries with it concepts and assumptions that are sometimes difficult to enact with uninitiated participants who in this study participated with much of the associated jargon, such as of root definitions and conceptual models, avoided in an effort to improve engagement (23). 
A related approach to addressing future health needs of communities is the action research pathway adopted by the Orjan Project in Sweden, which has transformed healthcare delivery resulting in cost savings and improved health outcomes through the development and implementation of integrated mobile 'meeting the patients where they are' care models (38). The Orjan Project was framed from a patient's perspective and included representatives from key stakeholders in the complex care system including patients, physicians, nurses, allied and community health workers, executives, politicians, labour unions and action researchers (38). With a patient-centred approach, stakeholders shared experiences, learnt from one another and coordinated action in a project that cumulatively allowed for continuous improvement and expansion, resulting in an $80 \%$ reduction in emergency visits, a $90 \%$ reduction in office visits and a $90 \%$ reduction in hospital admission days (39). Adopting this action research approach, where the patient's needs are pivotal to the co-design of programs, would challenge paramedic services to engage in a collaborative and fluid approach with unknown outcomes (40).

Even though paramedic services, given their 'command and control' organisational cultures, might be reluctant to view and engage the public as stakeholders in strategic decisions, the empowerment of patients to have a voice in how care is delivered is an important part of building trust and public acceptance throughout decision-making processes (32). As strategic objectives and key activities change throughout the process of time and innovation, stakeholders should be a dynamic concept, who may change or not be identified until the organisation's objectives are clearly defined (23). Paramedic services should be willing to embrace meaningful and collaborative partnerships with patients, broader health networks, social services, politicians and researchers; be prepared to step away from their traditional 'command and control' position; and be openly guided by the expertise and perspectives of others to co-design and achieve sustainable innovations.

\section{Conclusions}

Community paramedicine is a patient-centred holistic approach focussed on the improvement of health outcomes, with success heavily reliant on integrative partnerships forged between local paramedics, GPs, health and social service networks. This observation is consistent with the recognition that a 'one size fits all' approach to rural health is ineffective as it fails to align healthcare with local population needs. Active participation of stakeholders in the process of introducing CP programs, where people are comfortable questioning current practices and encouraged to explore new concepts and innovations will enable a shared understanding of program aims and expectations. Valuable lessons can be learnt from the Orjan Project, where stakeholders were engaged and represented across all domains to form an inclusive and diverse network that produced a successful mobile health program where the patients' perspective was imperative in framing the group's objectives and desired outcomes. Appreciating others' perspectives can alleviate tensions and misunderstandings that significantly impact on enhanced service delivery and improved organisational culture. In order for paramedic services to expand and improve service delivery models in rural Australia, the concept of community participation and holistic engagement with key stakeholders needs to be embraced. Establishing collaborative partnerships with key stakeholders, where others' expertise and perspectives are respected and embodied in the planning and implementation of CP programs is pivotal to codesigning sustainable healthcare innovations in the future.

\section{Acknowledgements}

We would like to sincerely thank Paramedics Australasia (South Australian Chapter) for hosting this workshop and all who participated in this research including South Australian Ambulance Service management, volunteers and staff. We would also like to thank La Trobe University for funding this research.

\section{Competing interests}

The authors have no competing interests. Each author of this paper has completed the ICMJE conflict of interest statement. Peter O'Meara is an Associate Editor of the Australasian Journal of Paramedicine.

\section{References}

1. Bigham BL, Kennedy SM, Drennan I, Morrison LJ. Expanding paramedic scope of practice in the community: a systematic review of the literature. Prehosp Emerg Care 2013;17:361-72.

2. Martin AC, O'Meara P. Perspectives from the frontline of two North American community paramedicine programs: an observational, ethnographic study. Rural Remote Health 2019;19.

3. O'Meara P, Ruest M, Martin A. Integrating a community paramedicine program with local health, aged care and social services: an observational ethnographic study. Australian Journal of Paramedicine 2015;12.

4. Long D, Clark M, Lim D, Devenish S. What's in a name? The confusion in nomenclature of low-acuity specialist roles in paramedicine. ibid. 2016;13.

5. Eastwood K, Morgans A, Smith K, et al. A novel approach for managing the growing demand for ambulance services by low-acuity patients. Aust Health Rev 2016;40:378-84.

6. O'Meara P, Wingrove G, Nolan M. Frontier and remote paramedicine practitioner models. Rural Remote Health 2018;18:4550.

7. Gainey CE, Brown HA, Gerard WC. Utilization of mobile integrated health providers during a flood disaster in South Carolina (USA). Prehosp Disaster Med 2018;33:432-5. 


\section{References (continued)}

8. Kizer K, Shore K, Moulin A. Community paramedicine: a promising model for integrating emergency and primary care. California report 2013;1-24. Available at: https:// health.ucdavis.edu/iphi/publications/reports/resources/ IPHI_CommunityParamedicineReport_Final\%20070913.pdf

9. O'Meara P, Stirling C, Ruest M, Martin A. Community paramedicine model of care: an observational, ethnographic case study. BMC Health Serv Res 2016;16.

10. Martin A, O'Meara P, Farmer J. Consumer perspectives of a community paramedicine program in rural Ontario. Aust $\mathrm{J}$ Rural Health 2016;24:278-83.

11. O'Meara PF. Community paramedics: a scoping review of their emergence and potential impact. International Paramedic Practice 2014;4:5-12.

12.Jensen JL, Travers AH, Marshall EG, et al. Insights into the implementation and operation of a novel paramedic longterm care program. Prehosp Emerg Care 2014;18:86-91.

13.Jensen JL, Travers AH, Bardua DJ, et al. Transport outcomes and dispatch determinants in a paramedic longterm care program: a pilot study. CJEM 2013;15:206.

14. Ruest M, Stitchman A, Day C. Evaluating the impact on 911 calls by an in-home programme with a multidisciplinary team. International Paramedic Practice 2012;1:125-32.

15. Nolan M, Hillier T, D'Angelo C. Community paramedicine in Canada - Emergency Medical Services Chiefs of Canada. 2012;57-80. Available at: www.renfrewparamedics.ca/wpcontent/uploads/2018/04/Community-Paramedic-Literature. pdf

16. Martin-Misener R, Downe-Wamboldt B, Cain E, Girouard M. Cost effectiveness and outcomes of a nurse practitionerparamedic-family physician model of care: the Long and Brier Islands study. Prim Health Care Res Dev 2009;10.

17. Brydges M, Denton M, Agarwal G. The CHAP-EMS health promotion program: a qualitative study on participants' views of the role of paramedics. BMC Health Serv Res 2016;16.

18.Drennan IR, Dainty KN, Hoogeveen P, et al. Expanding Paramedicine in the Community (EPIC): study protocol for a randomized controlled trial. Trials 2014;15.

19.Pang PSL, Liao M, Herron J, et al. Limited data to support improved outcomes after community paramedicine intervention: a systematic review. Am J Emerg Med 2019;37:960-4.

20. Krumperman K. Community paramedicine: a historical review of policy development. EMS Insider 2010;37:3-6.

21.Lezzoni LI, Dorner SC, Ajayi T. Community paramedicine: addressing questions and programs expand. N Engl J Med 2016;374:1107-9.

22.Augustsson $\mathrm{H}$, Churruca K, Braithwaite J. Re-energising the way we manage change in healthcare: the case for soft systems methodology and its application to evidence-based practice. BMC Health Serv Res 2019;19.

23.Wang W, Wenbin L, Mingers J. A systemic method for organisational stakeholder identification and analysis using soft systems methodology (SSM). Eur J Oper Res 2015;246:562-74.

24. Checkland PB. Soft systems methodology. Human Systems Management 1989;8:273-89.

25. Nguyen TT, Scognamillo DG, Comer CE. Revealing community perceptions for ecological restoration using a soft system methodology. Syst Pract Action Res 2019;32:429-42.

26.Bergvall-Kareborn B, Mirijamdotter A, Basden A. Basic principles of SSM modeling: an examination of CATWOE from a soft perspective. ibid. 2004;17:55-73.

27.Braithwaite J, Hindle D, ledema R, Westbrook JI. Introducing soft systems methodology plus (SSM+): why we need it and what it can contribute. Aust Health Rev 2002;25:195-202.

28. O'Meara PF, Hickson H, Higgins C. Starting the conversation: what are the issues for paramedic student clinical education? Australasian Journal of Paramedicine 2014;11.

29. Strauss A, Corbin J. Basics of qualitative research: grounded theory procedures and techniques. 2nd edn. Thousand Oaks, CA: Sage; 1998.

30.Checkland P. Soft systems methodology: a thirty year retrospective. Syst Res Behav Sci 2000;17(S1).

31.O'Meara P, Walker J, Stirling C, et al. The rural and remote ambulance paramedic: moving beyond emergency response. Report to the Council of Ambulance Authorities Inc. Charles Sturt University, Bathurst; 2006.

32. Wankhade P, Mackway-Jones K. Ambulance services. Leadership and management perspectives. Switzerland: Springer International Publishing; 2015.

33. O'Meara P, Kendall D, Kendall L. Working together for a sustainable urgent care system: a case study from south eastern Australia. Rural Remote Health 2004;4.

34. Reed B, Cowin L, O'Meara P, Wilson I. Professionalism and professionalisation in the discipline of paramedicine. Australasian Journal of Paramedicine 2019;16.

35. Johnston TM, Acker JJ. Using a sociological approach to answering questions about paramedic professionalism and identity. ibid. 2016;13.

36. Ivashkevich M, Fitzgerald M. A framework for implementing community paramedic programs in British Columbia.

Richmond, BC, Ambulance Paramedics of British Columbia. CUPE 873;2014. Available at: www.apbc.ca/ files/3814/0916/4457/APBC_Community_Paramedicine_ Framework.pdf

37. O'Meara P. Would a prehospital practitioner model improve patient care in rural Australia? Emerg Med J 2003;20:199203.

38.Bradbury H, Allen W, Apgar JM, et al. Healthcare transformation: action research linking local practices to national scale. In: Cooking with action research: Stories and resources for self and community transformation. Vol 1. Portland, Oregon, USA.: Action Research; 2017;15-38. 


\section{References (continued)}

39. Bradbury H, Waddell S, O'Brien K, et al. A call to action research for transformations: the times demand it. Action Res 2019;17:3-10.

40. Wankhade P, Wankhade P. Staff perceptions and changing role of pre-hospital profession in the UK ambulance services: an exploratory study. Int J Emerg Serv
2016;5:126-44.

41.Rasku T, Kaunonen M, Thyer E, Paavilainen E, Joronen $\mathrm{K}$. The core components of community paramedicine integrated care in primary care settings: a scoping review. Scand J Caring Sci 2019;33:508-21.

42. Kenny A, Hyett N, Sawtell J, et al. Community participation in rural health: a scoping review. BMC Health Serv Res 2013;13:64. 